\title{
Modifikasi Perencanaan Struktur Gedung Ibis Styles Hotel Tanah Abang Jakarta Pusat dengan Metode Beton Pracetak
}

\author{
Kusuma Indra Klana, Mudji Irmawan dan Endah Wahyuni \\ Departemen Teknik Sipil, Fakultas Teknik Sipil dan Perencanaan, Institut Teknologi Sepuluh Nopember (ITS) \\ e-mail:irmawan@ce.its.ac.id, endah@ce.its.ac.id
}

\begin{abstract}
Abstrak-Sistem pracetak adalah suatu proses produksi suatu elemen struktur bangunan yang dicetak di pabrikasi dimana tempat elemen struktur tersebut akan digunakan satu kesatuan dalam sebuah bangunan di tempat berbeda. Sistem ini memiliki keunggulan berupa mutu yang dapat dipantau, lebih presisi, serta pengerjaannya tidak terpengaruh cuaca karena dipabrikasi dalam pabrik. Tak hanya itu, bentuk struktur gedung yang tipikal juga menjadi keunggulan untuk penggunaan sistem pracetak ini. Agar dapat ditransportasikan, maka perlu diperhatikan kebutuhan tulangan saat pengangkatan. Dan juga agar elemen pracetak dapat terintegrasi dengan baik, maka sambungan haruslah dibuat semonolit mungkin. Sambungan yang tahan terhadap gempa (seismic resistant) dapat menggunakan sambungan basah pada balok dan kolom pracetak dapat menggantikan sambungan monolit biasa sedangkan grouted steel sleeves cocok digunakan untuk sambungan kolom - kolom pada bangunan yang berada di zona gempa. Dari hasil analisa yang dilakukan, elemen-elemen pracetak sesuai ketentuan SNI 2847:2013[5]. Kolom digunakan dimensi $80 \times 80 \mathrm{~cm}$, balok induk $50 / 75 \mathrm{~cm}$, dan tebal plat $12 \mathrm{~cm}$ dengan overtopping $5 \mathrm{~cm}$. Dengan mempertimbangkan metode agar mudah dikerjakan maka digunakan sambungan dengan campuran antar sambungan mekanik dan basah. Pada sambungan mekanik menggunakan bantuan NMB Splice Sleeve dan BECO Beam shoe yang termasuk mechanical splices tipe 2 menurut peraturan ACI 318 11.
\end{abstract}

Kata Kunci-Pracetak Kolom Balok Plat, Sambungan Basah, Mechanical Splices.

\section{PENDAHULUAN}

\section{A. Latar Belakang}

Para developer berlomba-lomba membangun gedung bertingkat untuk menangkap peluang. Baik developer maupun investor ingin agar pembangunan suatu gedung cepat terealisasi dan segera berfungsi. Diharapkan dengan cepatnya pembangunan dan berfungsinya bangunan semakin cepat untuk memetik hasil investasi yang tidak sedikit. Ditambah lokasinya yang terletak di Jalan Fachrudin Tanah Abang, Jakarta Pusat yang sangat ramai menuntut proyek semakin cepat selesai agar tidak mengganggu kegiatan ekonomi di sekitarnya.

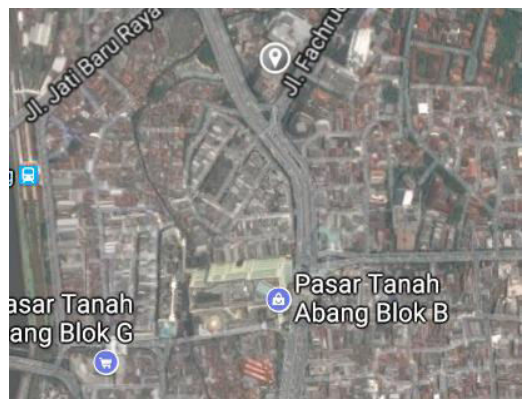

Gambar 1. Site Plan.

Sistem pracetak adalah suatu proses produksi suatu elemen struktur bangunan yang dicetak di pabrikasi dimana tempat elemen struktur tersebut akan digunakan satu kesatuan dalam sebuah bangunan di tempat berbeda. Sistem ini memiliki keunggulan berupa mutu yang dapat dipantau, lebih presisi, serta pengerjaannya tidak terpengaruh cuaca karena dipabrikasi dalam pabrik. Tak hanya itu, bentuk struktur gedung yang tipikal juga menjadi keunggulan untuk penggunaan sistem pracetak ini.

Oleh karena itu, pada Studi ini akan dilakukan modifikasi Gedung Ibis Styles Hotel Jakarta yang semula menggunakan metode sistem cor di tempat (case in site) menjadi dengan metode pracetak (precast).

\section{B. Rumusan Masalah}

1. Bagaimana menentukan preliminary design, struktur primer dan struktur sekunder yang sesuai dengan hasil perencanaan?

2. Bagaimana perhitungan pembebanan pada perencanaan struktur Gedung Ibis Styles Hotel?

3. Bagaimana melakukan analisa permodelan struktur Gedung Ibis Styles Hotel dengan menggunakan program bantu ETABS?

4. Bagaimana perencanaan detailing penulangan pada elemen pracetak sesuai peraturan?

5. Bagaimana perencanaan detailing sambungan pada elemen pracetak sesuai peraturan?

6. Bagaimana perencanaan struktur pondasi yang mampu menopang gedung?

7. Bagaimana merancang gambar teknik dari hasil modifikasi perancangan dan perhitungan struktur?

\section{URAIAN PERENCANAAN}

\section{A. Diagram Alir Perencanaan}

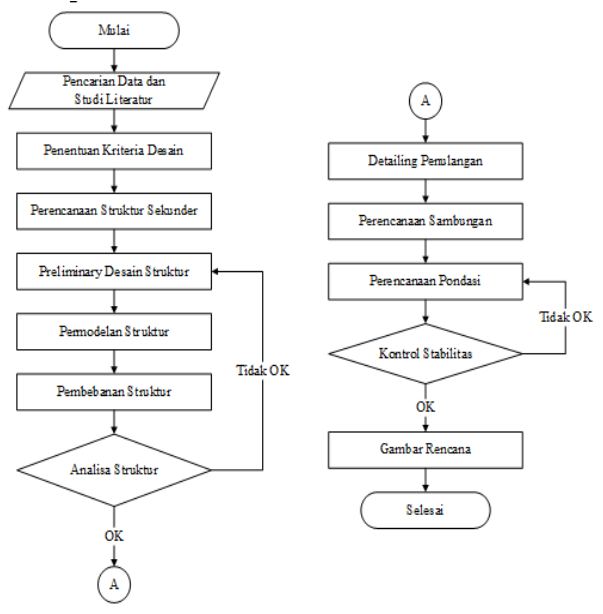

Gambar 2. Diagram alir penyelesaian Studi 


\section{B. Modifikasi dan Kriteria Pemilihan Struktur}

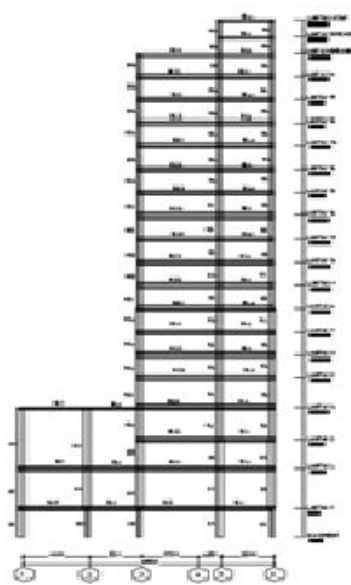

Gambar 3. Gambar Potongan Gedung.

Data - data setelah modifikasi:

- Nama gedung: Gedung Ibis Styles Hotel

- Lokasi

: Jl. Fachruddin no 6, Jakarta

- Fungsi

: Hotel dan Perkantoran

- Jumlah lantai

$: 18$

- Tinggi bangunan

$:+67,5 \mathrm{~m}$

- Total luas area

$: \pm 8600 \mathrm{~m}^{2}$

- Struktur utama

: Struktur beton pracetak

- Kekuatan tekan beton (f'c) = $40 \mathrm{MPa}$

- Tegangan leleh baja (fy) = $390 \mathrm{Mpa}$

\section{HASIL DAN PEMBAHASAN}

\section{A. Preliminary Design}

Untuk desain awal bangunan dapat dilihat pada Gambar 4

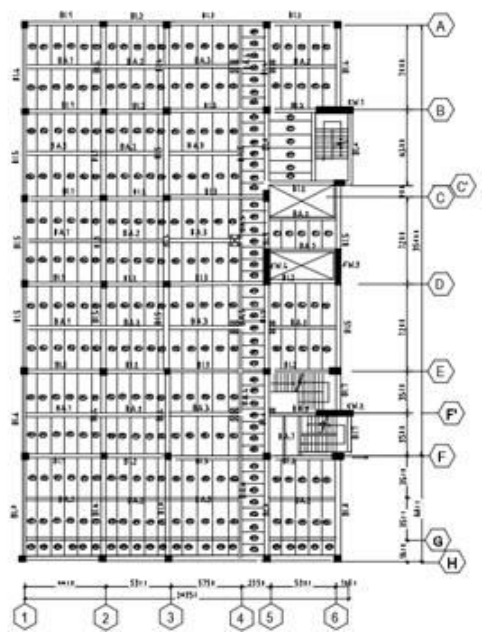

Gambar 4. Denah Struktur.

\section{Dimensi Balok}

Sesuai dengan SNI 2847:2013 pasal 9.5.2.1 tabel 9.5 (a) untuk dimensi balok yang direkapitulasi pada Tabel 1 dan Tabel 2.

Tabel 1.

Rekapitulasi Dimensi Balok Induk

\begin{tabular}{|c|c|c|c|c|c|c|c|}
\hline \multirow[b]{2}{*}{ Tipe Balok } & \multirow{2}{*}{ Bentang $(\mathrm{m})$} & \multicolumn{2}{|c|}{ Dimensi Min (m) } & \multicolumn{2}{|c|}{ Dimensi Min (cm) } & \multicolumn{2}{|c|}{ Dimensi Pakai $(\mathrm{cm})$} \\
\hline & & $\mathrm{b}$ & $\mathrm{h}$ & $\mathrm{b}$ & $\mathrm{h}$ & $\mathrm{b}$ & $\mathrm{h}$ \\
\hline BI.1 & 6,6 & 0,28 & 0,41 & 27,50 & 41,25 & 50 & 75 \\
\hline BI.2 & 5,3 & 0,22 & 0,33 & 22,08 & 33,13 & 50 & 75 \\
\hline BI.3 & 8,1 & 0,34 & 0,51 & 33,75 & 50,63 & 50 & 75 \\
\hline BI.4 & 7 & 0,29 & 0,44 & 29,17 & 43,75 & 50 & 75 \\
\hline BI.5 & 7,2 & 0,30 & 0,45 & 30,00 & 45,00 & 50 & 75 \\
\hline BI.6 & 8,8 & 0,37 & 0,55 & 36,67 & 55,00 & 50 & 75 \\
\hline
\end{tabular}

Tabel 2.

Rekapitulasi Dimensi Balok Anak

\begin{tabular}{|c|c|c|c|c|c|c|c|}
\hline \multirow{2}{*}{ Tipe Balok } & \multirow{2}{*}{$\begin{array}{c}\text { Bentang } \\
(\mathrm{m})\end{array}$} & \multicolumn{2}{|c|}{ Dimensi Min (m) } & \multicolumn{2}{|c|}{ Dimensi Min $(\mathrm{cm})$} & \multicolumn{2}{|c|}{ Dimensi Pakai $(\mathrm{cm})$} \\
\hline & & $\mathrm{b}$ & $\mathrm{h}$ & $\mathrm{b}$ & $\mathrm{h}$ & b & $\mathrm{h}$ \\
\hline BA.1 & 6,6 & 0,21 & 0,31 & 20,95 & 31,43 & 25 & 35 \\
\hline BA. 2 & 5,3 & 0,17 & 0,25 & 16,83 & 25,24 & 25 & 35 \\
\hline BA. 3 & 5,75 & 0,18 & 0,27 & 18,25 & 27,38 & 25 & 35 \\
\hline BA.4 & 7 & 0,22 & 0,33 & 22,22 & 33,33 & 35 & 55 \\
\hline BA. 5 & 7,2 & 0,23 & 0,34 & 22,86 & 34,29 & 35 & 55 \\
\hline BA.6 & 8,8 & 0,28 & 0,42 & 27,94 & 41,90 & 35 & 55 \\
\hline BA.7 & 3 & 0,10 & 0,14 & 9,52 & 14,29 & 25 & 35 \\
\hline BA.8 & 6 & 0,19 & 0,29 & 19 & 28,57 & 25 & 35 \\
\hline
\end{tabular}

2. Dimensi Pelat

Dimensi lebar plat pracetak satu arah tidak boleh melebihi 3,7 m [4]. Dari hasil perhitungan diperoleh tebal pelat yang dapat dilihat pada Tabel 3.

Tabel 3.

Rekapitulasi Tebal Pelat

\begin{tabular}{|c|c|c|c|c|c|c|c|}
\hline plat & ukuran $(\mathrm{cm})$ & Ln & Sn & $\beta$ & ket & hmin $(\mathrm{cm})$ & hpakai (cm) \\
\hline s1 & $350 \times 110$ & 320 & 75 & 4,27 & $\beta>2$ maka satu arah & 4,73 & 12 \\
\hline$s 2$ & $360 \times 110$ & 330 & 75 & 4,40 & $\beta>2$ maka satu arah & 4,80 & 12 \\
\hline$s 3$ & $350 \times 100$ & 320 & 65 & 4,92 & $\beta>2$ maka satu arah & 4,38 & 12 \\
\hline$s 4$ & $360 \times 100$ & 330 & 65 & 5,08 & $\beta>2$ maka satu arah & 4,44 & 12 \\
\hline$s 5$ & $350 \times 125$ & 320 & 92,5 & 3,46 & $\beta>2$ maka satu arah & 5,24 & 12 \\
\hline$s 6$ & $360 \times 125$ & 330 & 92,5 & 3,57 & $\beta>2$ maka satu arah & 5,33 & 12 \\
\hline$s 7$ & $285 \times 110$ & 252,5 & 75 & 3,37 & $\beta>2$ maka satu arah & 4,19 & 12 \\
\hline$s 8$ & $200 \times 100$ & 167,5 & 65 & 2,58 & $\beta>2$ maka satu arah & 3,11 & 12 \\
\hline$s 9$ & $235 \times 100$ & 195 & 65 & 3,00 & $\beta>2$ maka satu arah & 3,40 & 12 \\
\hline$s 10$ & $235 \times 110$ & 317,5 & 75 & 4,23 & $\beta>2$ maka satu arah & 4,71 & 12 \\
\hline$s 11$ & $180 \times 90$ & 497,5 & 65 & 7,65 & $\beta>2$ maka satu arah & 3,74 & 12 \\
\hline
\end{tabular}

\section{Dimensi Kolom}

Menurut SNI 2847:2013 pasal 9.3.2.2 (b) untuk komponen struktur beton bertulang lainnya faktor reduksi, $\Phi$ $=0,65$. Mutu beton $=40 \mathrm{MPa}=4 \mathrm{~kg} / \mathrm{mm}^{2}$.

Tabel 4.

Rekapitulasi Dimensi Kolom

\begin{tabular}{|l|l|l|}
\hline Tipe & Lantai & Dimensi \\
\hline K1 & basement - Lt 2 & $80 \times 80$ \\
\hline K2 & Lantai 3 - Lt 7 & $70 \times 70$ \\
\hline K3 & Lantai 8 - Lt 12 & $60 \times 60$ \\
\hline K4 & Lantai 13 - Lt 18 & $50 \times 50$ \\
\hline
\end{tabular}

4. Dimensi Dinding Geser

Berdasarkan peraturan SNI 2847:2013 pasal 14.5.3.1 ketebalan dinding pendukung tidak boleh kurang dari 1/25 tinggi, maka:

$T \geq H / 25$

$$
\begin{aligned}
& \frac{400}{25}=16 \mathrm{~cm} \\
& \frac{300}{25}=12 \mathrm{~cm}
\end{aligned}
$$

$T \geq L / 25$

Maka digunakan tebal dinding geser $40 \mathrm{~cm}$

\section{B. Desain Struktur Sekunder}

1. Penulangan Pelat Lantai

Kombinasi pembebanan yang digunakan:

$\mathrm{Qu} \quad=1,2 \mathrm{DL}+1,6 \mathrm{LL}$

Sehingga diperoleh hasil penulangan pelat sebagai berikut

Tabel 5.

\begin{tabular}{|c|c|c|c|c|c|c|c|}
\hline tipe plat & ukuran $(\mathrm{cm})$ & Tulangan Utama & Tulangan Pembagi & Tulangan Tumpuan & Stud & Profil Ancho & rofil Lifter \\
\hline s1 & $350 \times 110$ & D10-200 & D10-300 & D10-300 & D10-150 & PSA $14 \times 33$ & JL 14 \\
\hline s2 & $360 \times 110$ & D10-200 & D10-300 & D10-300 & D10-150 & PSA $14 \times 33$ & JL 14 \\
\hline s3 & $350 \times 100$ & D10-200 & D10-300 & D10-300 & D10-150 & PSA $14 \times 33$ & JL 14 \\
\hline$s 4$ & $360 \times 100$ & D10-200 & D10-300 & D10-300 & D10-150 & PSA $14 \times 33$ & JL 14 \\
\hline$s 5$ & $350 \times 125$ & D10-200 & D10-300 & D10-300 & D10-150 & PSA $14 \times 33$ & JL 14 \\
\hline$s 6$ & $360 \times 125$ & D10-200 & D10-300 & D10-300 & D10-150 & PSA $14 \times 33$ & JL 14 \\
\hline s7 & $285 \times 110$ & D10-200 & D10-300 & D10-300 & D10-150 & PSA $14 \times 33$ & JL 14 \\
\hline 58 & $200 \times 100$ & D10-200 & D10-300 & D10-300 & D10-150 & PSA $14 \times 33$ & JL 14 \\
\hline 59 & $235 \times 100$ & $D 10-200$ & D10-300 & D10-300 & D10-150 & PSA $14 \times 33$ & JL 14 \\
\hline$s 10$ & $235 \times 110$ & D10-200 & D10-300 & D10-300 & D10-150 & PSA $14 \times 33$ & IL 14 \\
\hline s11 & $180 \times 90$ & D10-200 & D10-300 & D10-300 & D10-150 & PSA $14 \times 33$ & JL 14 \\
\hline
\end{tabular}

Penulangan Pelat 


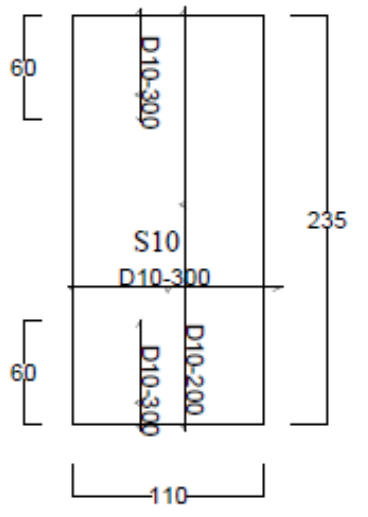

Gambar 5. Detail Penulangan Pelat.

2. Perencanaan Balok Anak

- Balok anak

Dari hasil perhitungan diperoleh kebutuhan tulangan tumpuan dan tulangan lapangan yang dapat dilihat pada Tabel 6 .

Tabel 6.

Penulangan Balok Anak

\begin{tabular}{|c|c|c|c|c|c|c|c|c|}
\hline \multirow{2}{*}{$\begin{array}{l}\text { Tipe } \\
\text { Balok }\end{array}$} & \multirow{2}{*}{$\begin{array}{l}\mathrm{Lb} \\
(\mathrm{m})\end{array}$} & \multicolumn{2}{|c|}{ Dimensi $(\mathrm{cm})$} & \multicolumn{2}{|c|}{ Tulangan Terpasang } & \multirow{2}{*}{$\begin{array}{l}\text { Tulangan } \\
\text { Sengkang }\end{array}$} & \multirow{2}{*}{ Profil Anchor } & \multirow{2}{*}{$\begin{array}{l}\text { Profil } \\
\text { Lifter }\end{array}$} \\
\hline & & $b$ & $\mathrm{~h}$ & Tumpuan & Lapangan & & & \\
\hline BA.1 & 6,6 & 25 & 35 & $2 \mathrm{D} 22$ & 2D22 & $\Phi 10-150$ & WAS $24 \times 240$ & JL 24 \\
\hline BA.2 & 5,3 & 25 & 35 & $2 \mathrm{D} 22$ & $2 \mathrm{D} 22$ & $\Phi 10-150$ & WAS $24 \times 240$ & JL 24 \\
\hline BA.3 & 5,75 & 25 & 35 & $2 \mathrm{D} 22$ & 2D22 & $\Phi 10-150$ & WAS $24 \times 240$ & JL 24 \\
\hline BA. 4 & 7 & 35 & 55 & 2D22 & 4D22 & $\Phi 10-150$ & WAS $24 \times 240$ & JL 24 \\
\hline BA. 5 & 7,2 & 35 & 55 & $2 \mathrm{D} 22$ & $4 \mathrm{D} 22$ & $\Phi 10-150$ & WAS $24 \times 240$ & JL 24 \\
\hline BA. 6 & 8,8 & 35 & 55 & $2 \mathrm{D} 22$ & $4 \mathrm{D} 22$ & $\Phi 10-150$ & WAS $30 \times 300$ & JL 30 \\
\hline BA.7 & 3 & 25 & 35 & 2D22 & 2D21 & $\Phi 10-150$ & WAS $24 \times 240$ & JL 24 \\
\hline BA.8 & 6 & 25 & 35 & $2 \mathrm{D} 22$ & $2 \mathrm{D} 22$ & $\Phi 10-150$ & WAS $24 \times 240$ & JL 24 \\
\hline
\end{tabular}

OVERTOPPING BETON COR PELAT PRACETAK

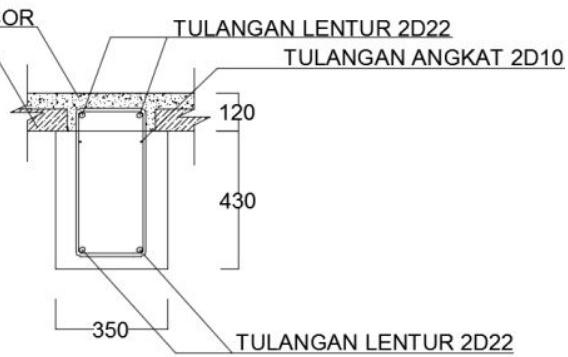

Gambar 6. Penulangan Balok Anak.

3. Desain Tangga

a. Penulangan Pelat Tangga

Data perencanaan:

- $\mathrm{f}^{\prime} \mathrm{c}=40 \mathrm{MPa}$

- fy $=390 \mathrm{MPa}$

Digunakan tulangan lentur arah X D10-300 mm

Digunakan tulangan lentur arah Y D13-200 mm

b. Penulangan Pelat Bordes

Data perencanaan:

- $\mathrm{f}^{\prime} \mathrm{c}=40 \mathrm{MPa}$

- $\mathrm{fy}=390 \mathrm{MPa}$

Digunakan tulangan lentur arah X D10-300 mm

Digunakan tulangan lentur arah Y D13-200 mm

c. Penulangan Balok Bordes

Dimensi balok bordes dipakai 35/55 cm

Digunakan tulangan tumpuan 2D16

Digunakan tulangan lapangan 3D16

Digunakan tulangan sengkang Ø10-150 mm

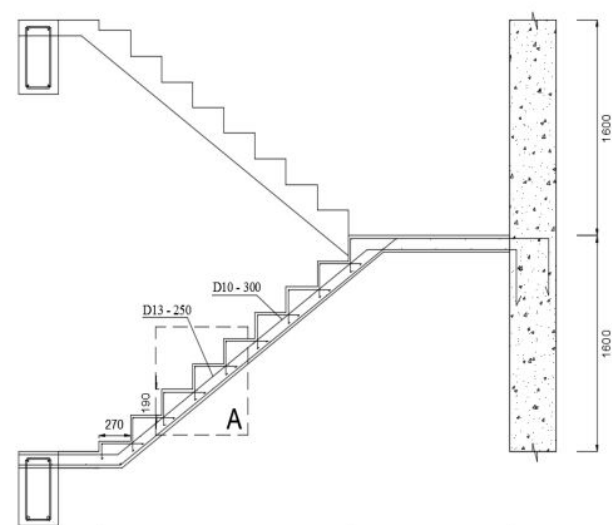

Gambar 7. Penulangan Tangga

4. Perhitungan Balok Lift

- Data perencanaan (Hospital Elevator)

Pada bangunan ini digunakan lift yang diproduksi oleh Hyundai Elevator dengan data - data sebagai berikut:

Tipe lift $\quad$ : Standard Type EN-81

Kapasitas : $1150 \mathrm{~kg}$

Beban reaksi ruang mesin:

- $\quad \mathrm{R} 1=6600 \mathrm{~kg}$

- $\quad \mathrm{R} 2=5500 \mathrm{~kg}$

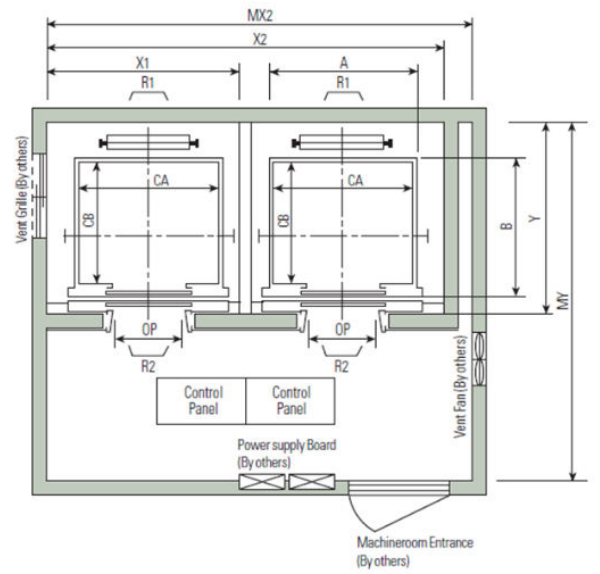

Gambar 8. Denah Lift.

Diperoleh dimensi balok:

- Balok penggantung lift $(35 / 50)$

- Balok penumpu (35/50)

C. Pembebanan dan Analisa Gaya Gempa

1. Kombinasi Beban Berfaktor

Kombinasi - kombinasi beban yang digunakan adalah sebagai berikut:

- 1,4DL

- $1,2 \mathrm{DL}+1,6 \mathrm{LL}$

- $1,2 \mathrm{DL}+1,0 \mathrm{LL}+1,0 \mathrm{Ex}$

- $1,2 \mathrm{DL}+1,0 \mathrm{LL}+1,0 \mathrm{Ey}$

- $1,0 \mathrm{DL}+1,0 \mathrm{LL}$

- $0,9 \mathrm{DL}+1,0 \mathrm{Ex}$

- $0,9 \mathrm{DL}+1,0 \mathrm{Ey}$

2. Data Perencanaan

Data - data analisis gempa yang akan digunakan adalah sebagai berikut: 
- Kelas Situs $\quad=\mathrm{SE}$

- Kategori Risiko = I

- Faktor keutamaan $=1$

- Ss

$$
=0,673 \mathrm{~g}
$$

- $\mathrm{S} 1$

$$
=0,296 \mathrm{~g}
$$

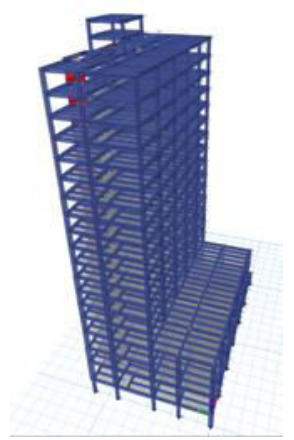

Gambar 9. Permodelan 3D Gedung.

\section{Pembebanan Gravitasi}

Pembebanan Gravitasi berupa beban mati dan beban hidup yang bekerja pada gedung. Beban mati dan hidup yang dipehitungkan berupa beban mati berdasarkan SNI 1726:2016 [3] dan beban hidup berdasarkan SNI 1727:2013[2].

Dari analisa pembebanan Gravitasi pada gedung Ibis Styles Hotel yang telah dilakukan didapatkan total beban secara manual (1D +1L) adalah $14964190 \mathrm{~kg}$

Didapatkan total beban gravitasi pada ETABS (1D+1L) sebesar $14899955 \mathrm{~kg}$. Sehingga didapatkan selisih perhitungan manual dengan ETABS $=1 \%$

Jadi dapat dikatakan bahwa pembebanan gravitasi pada ETABS sudah benar.

4. Pembebanan Gempa Dinamis

Pembebanan gempa dengan mengacu pada SNI 1726:2012, yang di dalamnya terdapat ketentuan dan persyaratan perhitungan beban gempa.

Daerah Surabaya dengan nilai Ss sebesar $0.663 \mathrm{~g}$ dan $\mathrm{S}_{1}$ sebesar 0,296 g. dengan faktor keutamaan dengan kategori I didapatkan $S_{D S}$ sebesar 0,673 dan kategori desain seismic tergolong kategori $\mathrm{E}$ sehingga gedung direncanakan menggunakan Sistem Ganda yaitu Dinding Geser Beton Bertulang Khusus dan Sistem Rangka Pemikul Momen Khusus (SRPMK).

Dari analisa program abntu ETABS didapatkan hasil analisa periode fundamental gedung $\mathrm{T}=2,175$ detik, $\mathrm{T}$ tidak boleh melebihi hasil koefisien untuk batasan atas pada perioda yang dihitung $(\mathrm{Cu}) . T_{a}<T_{a E T A B S}<C_{u} \times T_{a}$

$$
1,934<2,013<2,708
$$

Sehingga besarnya Cs diambil sebesar 0,0401, sehingga didapatkan berat seismic efektif bangunan (W) sebagai berikut $14899955 \mathrm{~kg}$

Gaya geser yang telah didapatkan dari perhitungan di atas akan didistribusikan secara vertikal ke masing-masing lantai sesuai dengan SNI 1726:2012.

$C s=0,0401 ; \mathrm{W}=14899955 \mathrm{~kg}$

$$
V=C_{s} \times W
$$

$$
V=0,0401 \times 14899955 \mathrm{~kg}=598493,69 \mathrm{~kg}
$$

Jika kombinasi respons untuk geser dasar ragam $(\mathrm{Vt})$ lebih kecil 85 persen dari geser dasar yang dihitung (V) menggunakan prosedur gaya lateral ekivalen, maka gaya harus dikalikan dengan 0,85V/Vt (SNI 1726:2012 Pasal 7.9.4.1).

Dari hasil analisa struktur menggunakan program bantu ETABS didapatkan gaya geser dasar ragam (Vt) sebagai berikut $\mathrm{Vxt}=\mathbf{5 0 8 8 1 2 , 7 1} \mathbf{~ k g}, \mathrm{Vyt}=\mathbf{5 0 8 8 7 1 , 7 1} \mathbf{~ k g}$

5. Kontrol Partisipasi Massa

Sesuai dengan SNI 1726:2012 pasal 7.9.1, Perhitungan respons dinamik struktur harus sedemikian rupa sehingga partisipasi massa dalam menghasilkan respon total sekurang kurangnya adalah $90 \%$.

Tabel 7.

Partisipasi Massa

\begin{tabular}{|l|r|r|r|r|r|r|r|r|}
\hline \multicolumn{1}{|c|}{ TABLE: Modal Participating Mass Ratios } \\
\hline \multicolumn{1}{|c|}{ Case } & Mode & Period & UX & UY & UZ & Sum UX & Sum UY & Sum UZ \\
\hline & & sec & & & & & & \\
\hline Modal & 1 & 2,013 & 0,688 & 0,007 & 0 & 0,688 & 0,007 & 0 \\
\hline Modal & 2 & 1,948 & 0,007 & 0,678 & 0 & 0,696 & 0,685 & 0 \\
\hline Modal & 3 & 1,630 & 0,003 & 0,000 & 0 & 0,698 & 0,685 & 0 \\
\hline Modal & 4 & 0,654 & 0,121 & 0,000 & 0 & 0,820 & 0,685 & 0 \\
\hline Modal & 5 & 0,628 & 0,000 & 0,138 & 0 & 0,820 & 0,823 & 0 \\
\hline Modal & 6 & 0,539 & 0,004 & 0,001 & 0 & 0,823 & 0,824 & 0 \\
\hline Modal & 7 & 0,355 & 0,050 & 0,000 & 0 & 0,873 & 0,824 & 0 \\
\hline Modal & 8 & 0,321 & 0,001 & 0,054 & 0 & 0,874 & 0,878 & 0 \\
\hline Modal & 9 & 0,278 & 0,004 & 0,001 & 0 & 0,878 & 0,880 & 0 \\
\hline Modal & 10 & 0,219 & 0,028 & 0,001 & 0 & 0,905 & 0,880 & 0 \\
\hline Modal & 11 & 0,202 & 0,001 & 0,030 & 0 & 0,907 & 0,910 & 0 \\
\hline Modal & 12 & 0,172 & 0,001 & 0,001 & 0 & 0,908 & 0,911 & 0 \\
\hline
\end{tabular}

6. Kontrol Sistem Ganda

Untuk sistem ganda, rangka pemikul momen harus mampu menahan paling sedikit 25 persen gaya gempa desain. Tahanan gaya gempa total harus disediakan oleh kombinasi rangka pemikul momen dan dinding geser atau rangka bresing, dengan distribusi yang proporsional terhadap kekakuannya.

Tabel 8.

Persentase Gaya Geser yang Mampu Dipikul Sistem Struktur

\begin{tabular}{lllll}
\hline \hline $\begin{array}{l}\text { Pemikul Gaya } \\
\text { Geser }\end{array}$ & Arah X $(\mathrm{kN})$ & $\%$ & Arah Y $(\mathrm{kN})$ & $\%$ \\
\hline Dinding Geser & 3628,932 & $71 \%$ & 3805,942 & $74,2 \%$ \\
Sistem Rangka & 1428,230 & $29 \%$ & 1323,361 & $25,8 \%$ \\
Total & 5111,172 & OK & 5129,303 & OK \\
\hline \hline
\end{tabular}

\section{Perencanaan Struktur Primer}

\section{Penulangan Balok Induk}

Balok induk direncanakan pada 2 keadaan yaitu saat sebelum komposit dengan plat dan sesudah komposit. Gambar penulangan seperti gambar berikut.

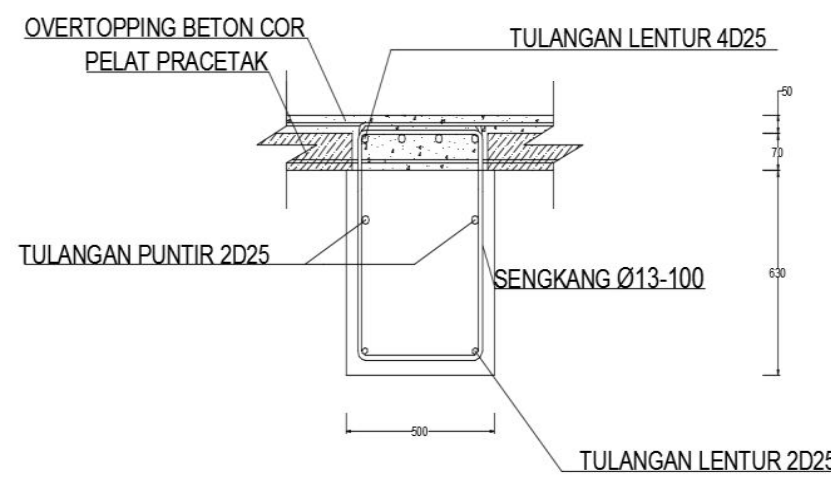


Gambar 10. Penulangan Balok Induk.

Dari hasil perhitungan diperoleh balok dimensi 50/75 dengan kebutuhan tulangan tumpuan, lapangan dan geser yang dapat dilihat pada Tabel 9.

Tabel 9.

Penulangan Balok Induk

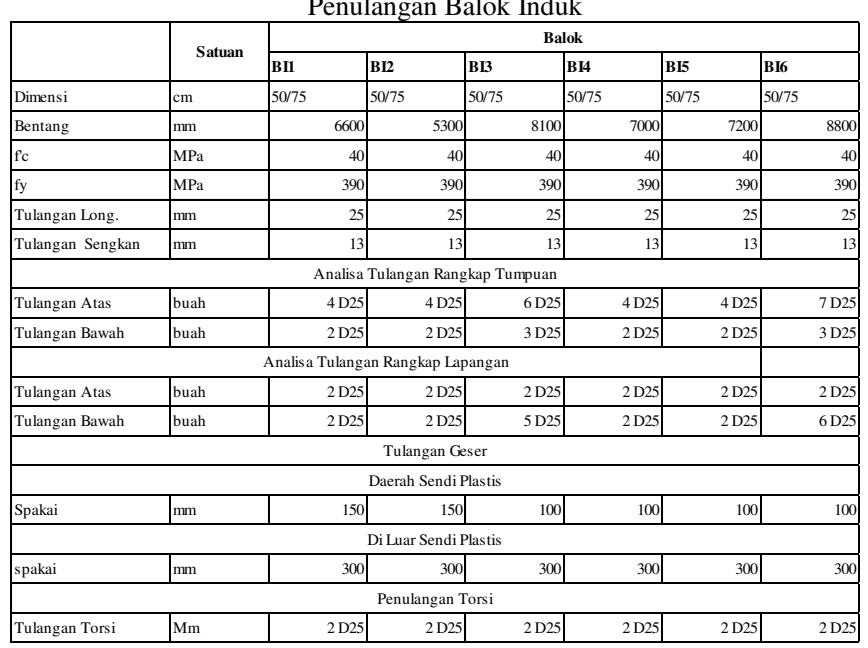

2. Penulangan Lentur Kolom

Berdasarkan SNI 2847:13, pasal 16.5.1.3 (a), kolom pracetak harus mempunyai kekuatan nominal dalam kondisi tarik tidak kurang dari 1,4Ag dalam N (Gambar 11).

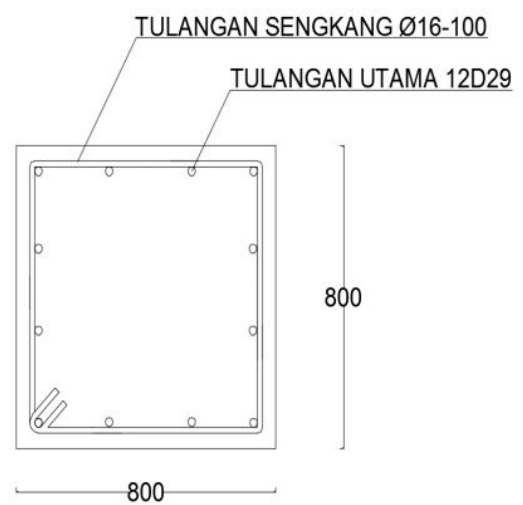

Gambar 11. Penulangan Kolom.

Penulangan lentur kolom menggunakan program bantu spColumn sehingga didapatkan hasil sebagai berikut:

Tabel 10.

Rekapitulasi Kolom

\begin{tabular}{|l|l|l|l|l|r|r|}
\hline Parameter & Satuan & K1 & K2 & K3 & K4 \\
\hline \multicolumn{7}{|c|}{ Data Perencanaan } \\
\hline Dimensi & $\mathrm{cm}$ & $80 / 80$ & $70 / 70$ & $60 / 60$ & $50 / 50$ \\
\hline $\mathrm{f}^{\prime} \mathrm{c}$ & $\mathrm{MPa}$ & 40 & 40 & 40 & 40 \\
\hline Fy & $\mathrm{MPa}$ & 390 & 390 & 390 & 390 \\
\hline Tul. Pakai & & $12 \mathrm{D} 29$ & $12 \mathrm{D} 29$ & $12 \mathrm{D} 29$ & $12 \mathrm{D} 29$ \\
\hline As & $\mathrm{mm}^{2}$ & 7740 & 7740 & 7740 & 7740 \\
\hline Rho & & $1.21 \%$ & $1,58 \%$ & $2,15 \%$ & $3,10 \%$ \\
\hline $1 \%<\rho<6 \%$ & kontrol & OK & OK & OK & OK \\
\hline$>1,4 \mathrm{Ag}$ & kontrol & OK & OK & OK & OK \\
\hline
\end{tabular}

3. Penulangan Dinding Geser

- Dinding geser horizontal $=2 \mathrm{D} 13-250 \mathrm{~mm}$ (Arah X dan Y)

- Dinding geser vertikal $=2 \mathrm{D} 13-250 \mathrm{~mm}($ Arah X dan Y)
- Boundary Element =12D 29

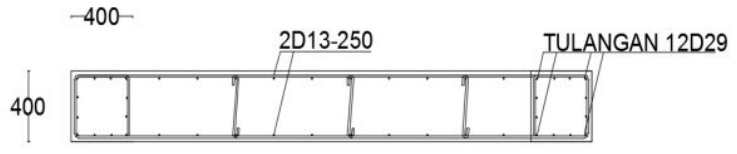

Gambar 12. Penulangan Dinding Geser.

\section{E. Perencanaan Sambungan}

1. Sambungan Poer dan Kolom

Sesuai ACI 318-11 pasal 21.1.6.2 dan pasal 21.8.3 (d)

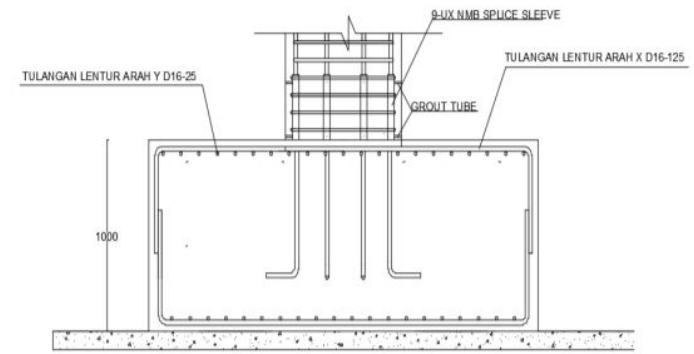

Gambar 13. Sambungan Poer dan Kolom 1.

2. Sambungan Kolom dan Kolom

Sesuai ACI 318-11 pasal 21.1.6.2 dan pasal 21.8.3

(d)

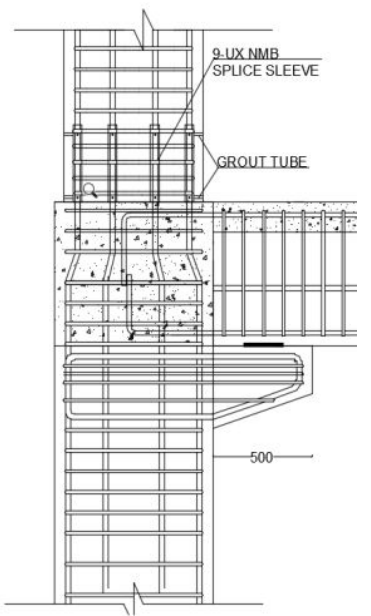

Gambar 14. Penulangan Kolom 1 dan Kolom 2.

3. Sambungan Balok dan Kolom

Sesuai dengan SNI 2847:2013 pasal 11.8

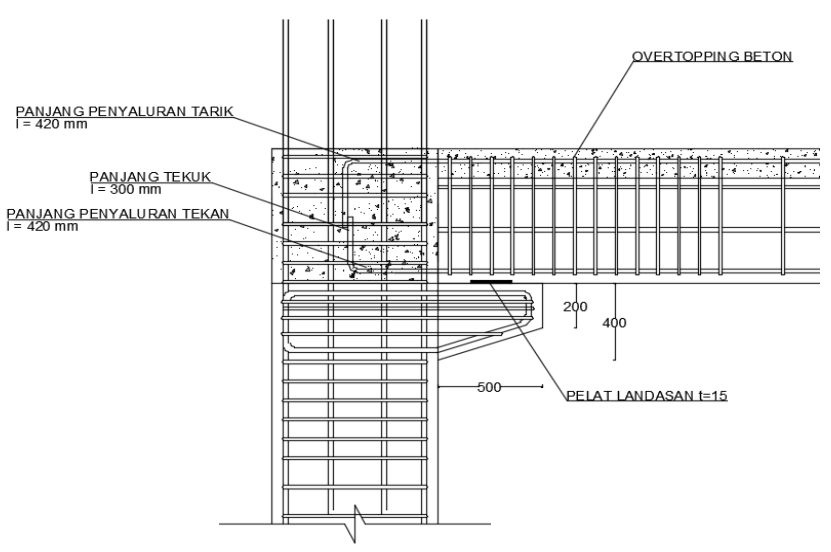


Gambar 15. Sambungan balok dan kolom 1.

4. Sambungan balok induk dan balok anak

Penyaluran momen negative tumpuan menggunakan SNI 2847:2013 pasal 11.8 namun momen positif tumpuan sesuai ACI 318-11 pasal 21.6.2 dan pasal 21.8 .3 (c).

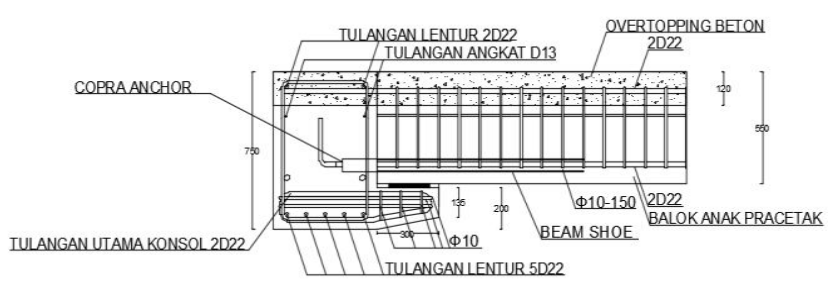

Gambar 16. Sambungan balok induk dan balok anak.

5. Sambungan balok dengan pelat

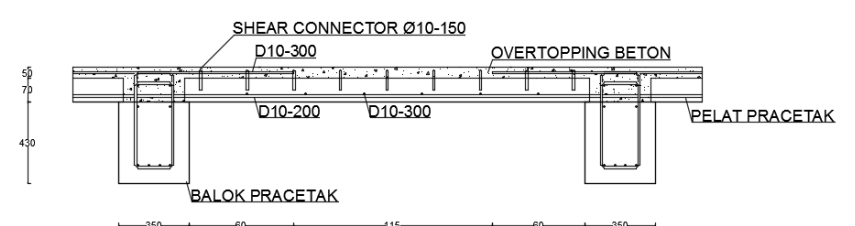

Gambar 17. Sambungan balok dan pelat.

\section{F. Perencanaan Struktur Bawah}

\section{Pembebanan}

Beban struktur menentukan bagaimana perencanaan pondasi yang akan dilakukan. beban struktur disalurkan melalui kolom kemudian ke tiang pancang. Beban yang bekerja pada pondasi dihitung menurut SNI 1726:2012 pasal 2.4.1 kombinasi beban untuk metoda tegangan ijin. Kombinasi beban-beban dibawh ini adalah kombinasi beban untuk menghitung tiang pancang dengan desain tegangan ijin.

$$
\begin{array}{ll}
- & 1 \mathrm{D} \\
- & \mathrm{D}+\mathrm{L} \\
- & \mathrm{D}+0,75 \mathrm{~L} \\
- & \mathrm{D}+0,7 \mathrm{E} \\
- & \mathrm{D}+0,75 \mathrm{~L}+0,75(0,7 \mathrm{E}) \\
\text { - } & 0,6 \mathrm{D}+0,7 \mathrm{E}
\end{array}
$$

2. Analisis Daya Dukung Tiang Pancang

Perhitungan daya dukung pondasi tiang pancang menggunakan metode Luciano Decourt

$$
\mathrm{Q}_{\mathrm{L}}=\mathrm{Q}_{\mathrm{P}}+\mathrm{Q}_{\mathrm{S}}
$$

Di mana:

$\mathrm{Q}_{\mathrm{L}} \quad$ = daya dukung tanah maksimum pada pondasi

$\mathrm{Q}_{\mathrm{P}} \quad=$ resistance ultimate di dasar pondasi

$\mathrm{Q}_{\mathrm{S}} \quad=$ resistance ultimate akibat lekatan lateral

3. Perancangan Pondasi Tiang Pancang

Dari hasil perhitungan yang telah dilakukan diperoleh hasil pondasi kolom menggunakan Spun Pile sebanyak 4 buah dengan spesifikasi sebagai berikut:

$\begin{array}{ll}\text { Diameter outside }(D) & : 600 \mathrm{~mm} \\ \text { Thickness } & : 100 \mathrm{~mm} \\ \text { Bending momen crack } & : 29 \mathrm{tm} \\ \text { Bending momen ultimate } & : 58 \mathrm{tm} \\ \text { Allowable axial } & : 229,5 \mathrm{t} \\ \text { Jarak antar tiang pancang } & : 1500 \mathrm{~mm} \\ \text { Jarak tiang pancang ke tepi } & : 600 \mathrm{~mm}\end{array}$

\section{KESIMPULAN}

\section{A. Kesimpulan}

Berdasarkan perencanaan struktur yang dilakukan dalam penyusunan Studi "Modifikasi Perencanaan Struktur Gedung Ibis Styles Hotel Tanah Abang Jakarta Pusat Dengan Metode Beton Pracetak" maka disimpulkan beberapa data sebagai berikut:

1. Berdasarkan SNI 2847:2013 dan SNI 7833:2012 didapatkan perhitungan tebal dimensi struktur sekunder dan struktur primer dari beberapa elemen struktur berikut:

a. Struktur Sekunder

Dimensi balok anak

Dimensi balok bordes tangga

$$
=25 / 35 \mathrm{~cm}
$$$$
=35 / 55 \mathrm{~cm}
$$

Dimensi penggantung lift

Dimensi penumpu lift

$=35 / 50 \mathrm{~cm}$

Tebal pelat

$=35 / 50 \mathrm{~cm}$

$=12 \mathrm{~cm}$

b. Struktur Primer

$\begin{array}{ll}\text { Dimensi balok induk } & =50 / 75 \mathrm{~cm} \\ \text { Dimensi kolom } & =80 / 80 \mathrm{~cm} \\ \text { Dimensi pilecap } & =2,7 \times 2,7 \times 1 \mathrm{~m} \\ \text { Tiang pancang } & =D 60, H=44 \mathrm{~m} \\ \text { Tebal shearwall } & =40 \mathrm{~cm}\end{array}$

2. Perhitungan respon spectrum dengan bantuan puskim.pu.go.id wilayah gempa Jakarta dan perhitungannya berdasarkan SNI 1726:2012. Perhitungan pembebanan berdasarkan SNI 1727:2013.

3. Analisa gaya dalam struktur gedung menggunakan program bantu ETABS. Gaya yang dimasukkan dalam permodelan adalah beban mati dan beban hidup berdasarkan peraturan di atas.

4. Detailing penulangan elemen pracetak hampir sama dengan elemen cor setempat, sehingga sesuai dengan SNI 2847:2013

5. Penyambungan elemen pracetak menggunakan produk sambungan dari BECO Beam Shoe dan NMB Splice Sleeve dengan mutu 1,5 fy sehingga masuk dalam kategori mechanical coupler tipe 2 sesuai ACI 318-11. Untuk elemen yang disambung secara basah dalam analisa panjang penyaluran dihitung berdasarkan persyaratan SNI 2847:2013

6. Pondasi yang direncanakan sesuai dengan ketentuan perhitungan tiang pancang (spun pile) produk dari WIKA Beton dengan metode tengangan ijin dan pile cap (poer) berdasarkan metode tengangan ultimate.

7. Hasil analisa struktur yang telah dilakukan pada Gedung Ibis Styles Hotel digambar dengan program bantu AutoCad terlampir.

\section{B. Saran}

Berdasarkan analisa secara keseluruhan dari proses penyusunan Studi ini, beberapa saran yang dapat disampaikan oleh penulis diantaranya adalah :

1. Macam komponen pracetak sebaiknya tidak terlalu banyak. Dengan begitu bekisting menjadi lebih hemat, pengerjaan dilapangan menjadi lebih mudah dan cepat.

2. Dalam pengembangan ke depannya elemen dinding geser bisa dibuat pracetak jika memenuhi ketentuan dalam peraturan yang ada.

3. Aspek biaya diperhitungkan agar dapat diketahui kelebihan dan kekurangannya dari segi ekonomi. 


\section{DAFTAR PUSTAKA}

[1] ACI. ACI 318-11 Building Code Requirements for Structural Concrete. U.S.A : American Concrete Institute.

[2] Badan Standarisasi Nasional. 2012. Tata Cara Perhitungan Pembebanan Untuk Bangunan Rumah dan Gedung ( RSNI 1727:2013). Jakarta: Badan Standar Nasional.

[3] Badan Standarisasi Nasional. 2012. Tata Cara Perencanaan Ketahanan Gempa untuk Struktur Bangunan Gedung dan Non Gedung ( SNI 1726:2012 ). Jakarta: Badan Standar Nasional.

[4] Badan Standarisasi Nasional. 2013. Tata cara perancangan beton pracetak dan beton prategang untuk bangunan gedung ( SNI 7833:2012 ). Jakarta: Badan Standar Nasional.
[5] Badan Standarisasi Nasional. 2013. Tata cara Perhitungan Struktur Beton Untuk Bangunan Gedung ( SNI 2847:2013 ). Jakarta: Badan Standar Nasional.

[6] Patel, Paresh V., Nimse Rohit B., Joshi, Digesh D. 2014. Behavior of Wet Precast Beam Column Connections Under Progressive Collapse Scenario: an Experimental Study. Int J Adv Struct Eng. 158.

[7] Andrea Belleri, dan Paolo Riva. 2012. Seismic performance and retrofit of precast concrete grouted sleeve connections. PCI Journal Winter. 107. 